\title{
Metal intensity of structural roof slab under different supporting conditions
}

\author{
Andrey Vasilkin", and Gulnaz. Zhaparalieva \\ Moscow State University of Civil Engineering, Yaroslavskoe shosse, 26, Moscow, 129337, Russia
}

\begin{abstract}
The article presents and solves the problem of finding the design of minimum weight structural slab roof for given steel class, element crosssection type, and loading conditions. Structural roof slabs are widely used for large-span public and industrial buildings and allow a wide variety of structural and architectural forms. At the same time, the placement of supports was changed. In total, 10 options for the supports placement for the $36 \times 36 \mathrm{~m}$ structural slab and 6 options for the topology were considered. After applying the load, structure's strain-stress distribution was determined numerically, a cross-section was selected and its weight was calculated. Then, different options of support were compared in terms of structure weight. In fact, the article solved optimization problem by optimality criterion of metal intensity, restrictions in the form of overall dimensions, topology and strength conditions.
\end{abstract}

\section{Introduction}

Structural roof slabs are spatial core structures with a multiplication figure a certain shape, the so-called crystal. Slabs are used for cover spans in public and industrial buildings: exhibition halls, airports, museums, markets, garages, warehouses, etc. [1,2]. The advantage of structural slabs is high architectural expression and visual plasticity, as well as multi-connectedness, which helps to improve the survivability of the structure [3].

In first stages of structural slab design, engineer faces important task of selecting the space planning and structural solution of structure. As a rule, dimensions in plan and height of structure is determined by functional purpose, sometimes limiting the columns placement. The other parameters of structure, such as slab height, crystal type, crystal dimensions, type of cross-section of element can vary, i.e. be taken as variable parameters. Final design variant is usually the most efficient or optimal according to adopted optimality criterion. In the case of structural slabs, varying supports along the perimeter of slab, varying the slab height and the mesh size can be considered as variable parameters. Influence of slab strain-stress distribution, height and mesh size, as well as of vertical misalignment of support nodes on the structure's deflection are considered in a number of works [7,8]. Influence of supports placement on building perimeter is studied in article [9]. In present article, we will consider the influence of supports placement with the structural slab formation cantilever structural scheme.

\footnotetext{
* Corresponding author: vasilkinaa@mgsu.ru
} 


\section{Problem statement}

The present study solves the problem of finding optimal design solution for structural roof slab according to optimality criterion of metal intensity, depending on variable parameter - the supports placement.

Minimal weight as an optimality criterion is the most common for building structures, because it can be formalized [10].

Structural slabs with dimensions in plan $36 \times 36 \mathrm{~m}$, having an orthogonal belts grid with a mesh of $3.0 \times 3.0 \mathrm{~m}$ and a height along the belts axes of $2.12 \mathrm{~m}$ were adopted for study. The crystals of structural slab have a pyramidal shape with a square base. Influence of columns weight on metal intensity was not considered, since their weight, depending on height, is from 2 to $5 \%$ of entire structure weight, and depends on purpose of design object (according to Series 1.466-2 Spatial lattice structures of pipes type "Kislovodsk"). The columns work was modeled in the form of backstop - movement prohibition along the Z-axis.

Jointing of elements in the nodes is assumed to be hinged, the element sections are made of hot-rolled seamless steel pipe according to GOST 8732-78. Acting load, crystal type, slab height are accepted as unchangeable parameters. During the study, it was decided to limit the supports number, taking it to be equal to four, and in the future only change their placement. To calculate the design, we used LIRA CAD 2016 calculation complex based on finite element method.

The following loads were accepted as effective loads:

1. Constant load -structure's own weight, which was set automatically by PC LIRA CAD 2016 and changed at each selection iteration of element cross-sections.

2. Snow load is $1.5 \mathrm{kN} / \mathrm{m} 2$. Since the slope of upper structure belt $\alpha<30^{\circ}$, then according to SP 20.1330.2016 it is assumed an even snow cover distribution of over entire pavement.

3. It was decided not to take into account the wind load, since studies [11] show that the share of forces influence from the wind load on formation of structural slab strain-stress distribution is about $1 \%$.

In calculation scheme, distributed load from slab and snow was applied to all elements of upper structural slab belt as a uniformly distributed load, which corresponds to a no-span type of slab.

To perform the calculation, we created a spatial structural slab model with six degrees of freedom in each node. The type of all structural elements was set as truss, i.e. only axial forces (N) were used in the calculation. The ultimate flexibility of structural elements was $180-60 \alpha$.

To determine the structure stress-strain state, a static calculation was performed. When selecting and verifying sections of compressed elements, stability calculation was used, while tensile elements were calculated with strength calculation. Also, flexibility limitations of compressed and stretched elements were introduced in calculation (according to the Recommendations on the design of structural structures of the Kucherenko Central Research Institute of Nuclear Power Engineering).

For a more accurate analysis of dependence between the placement of structural slab support nodes and its stress-strain state, it was decided not to limit the element section types number. Such a solution makes it possible to obtain the most objective picture of stress distribution in the structural slab and cost- effectiveness of each structural solution.

For all elements of structural slab, steel class C245 was adopted. The calculation of steel structures was made within the steel elastic operation. 


\section{Calculation results}

In the first stage, several support options were specified as shown in Table 1 and Fig.1. Fig. 2 shows a longitudinal section of structure and deformed diagram for first support type.

Table 1.Calculation of possible support options

\begin{tabular}{|c|c|}
\hline Option number & Type of support \\
\hline 1 & with struts (supports in $\mathrm{p} .1,2,3,4)$ \\
\hline 2 & point 1 \\
\hline 3 & point 2 \\
\hline 4 & point 3 \\
\hline 5 & point 4 \\
\hline
\end{tabular}

For each options performed the calculation of design and determined its metal-intensity. The calculation results are shown in Table 2.

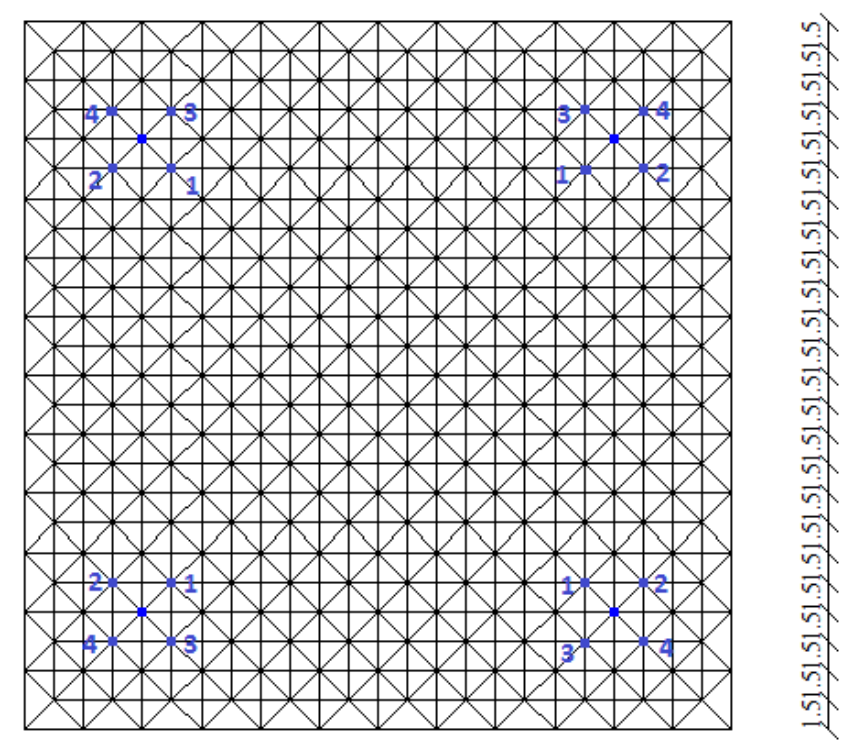

1.51 .51 .51 .51 .51 .51 .51 .51 .51 .51 .51 .51 .51 .51 .51 .51 .51 .51 .51 .51 .51 .51 .51 .5

Fig. 1. Slab support points

In first version, the calculations were carried out according to method of supporting the structural slab on struts with a hinge. The distance between columns is $24 \mathrm{~m}$.

a)

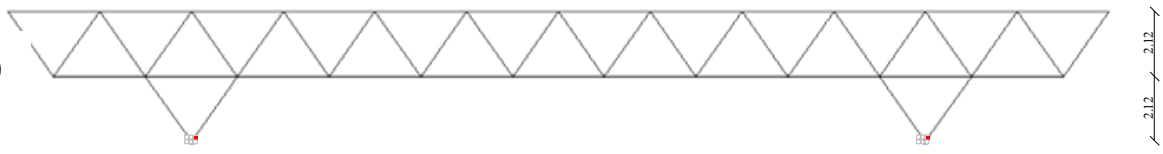


b)

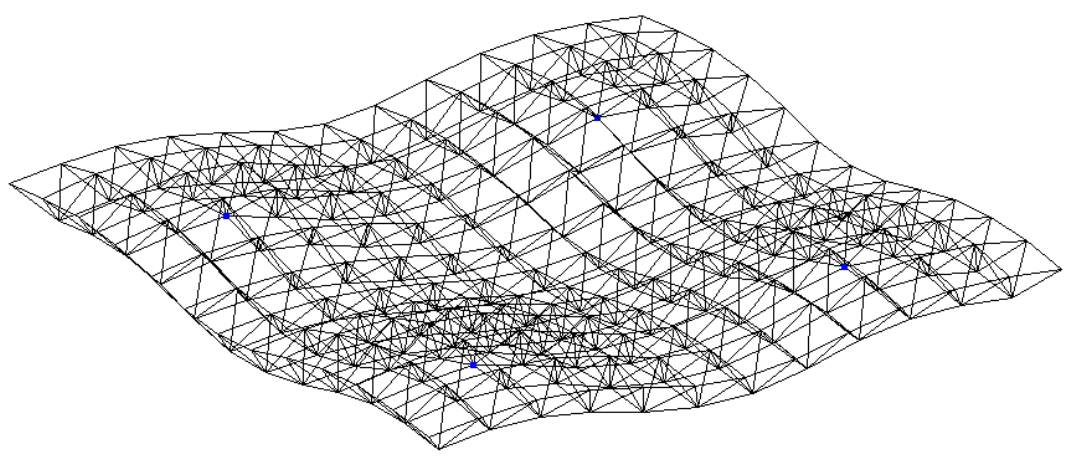

Fig. 2. Supporting the structural slab for option 1

a - scheme of supporting;

$\mathrm{b}$ - deformed scheme

Table 2.Metal intensity of structural slab $36 \times 36 \mathrm{~m}$

\begin{tabular}{|c|c|c|c|c|}
\hline $\begin{array}{c}\text { Option } \\
\text { number }\end{array}$ & Type of support & $\begin{array}{c}\text { Weight of structure } \\
\text { without unification, } \mathrm{t}\end{array}$ & Difference, $\%$ & $\begin{array}{c}\text { Number of } \\
\text { sectional calibers }\end{array}$ \\
\hline \multirow{2}{*}{$1^{*}$} & $\begin{array}{c}\text { with struts (supports in } \\
\text { p. } 1,2,3,4)\end{array}$ & 15.223 & $133 \%$ & \multirow{2}{*}{67} \\
\cline { 2 - 4 } & without struts & 14.115 & $123 \%$ & 58 \\
\hline 2 & point 1 & 11.433 & $100 \%$ & 106 \\
\hline 3 & point 2 & 17.210 & $151 \%$ & 115 \\
\hline 4 & point 3 & 17.612 & $154 \%$ & 125 \\
\hline 5 & point 4 & 22.940 & $201 \%$ & \\
\hline
\end{tabular}

* Typical variant Kislovodsk

Thus, it follows from presented results that optimal support is in p.1. In this case, crosssectional dimensions number of structural elements was not limited.

Next, consider how structure weight will change when the fulcrum is moved symmetrically about the main symmetry axes. Fig. 3, numbered 1-6, shows the support placements the points within structure contour. The calculations results are shown in Table 3 . 

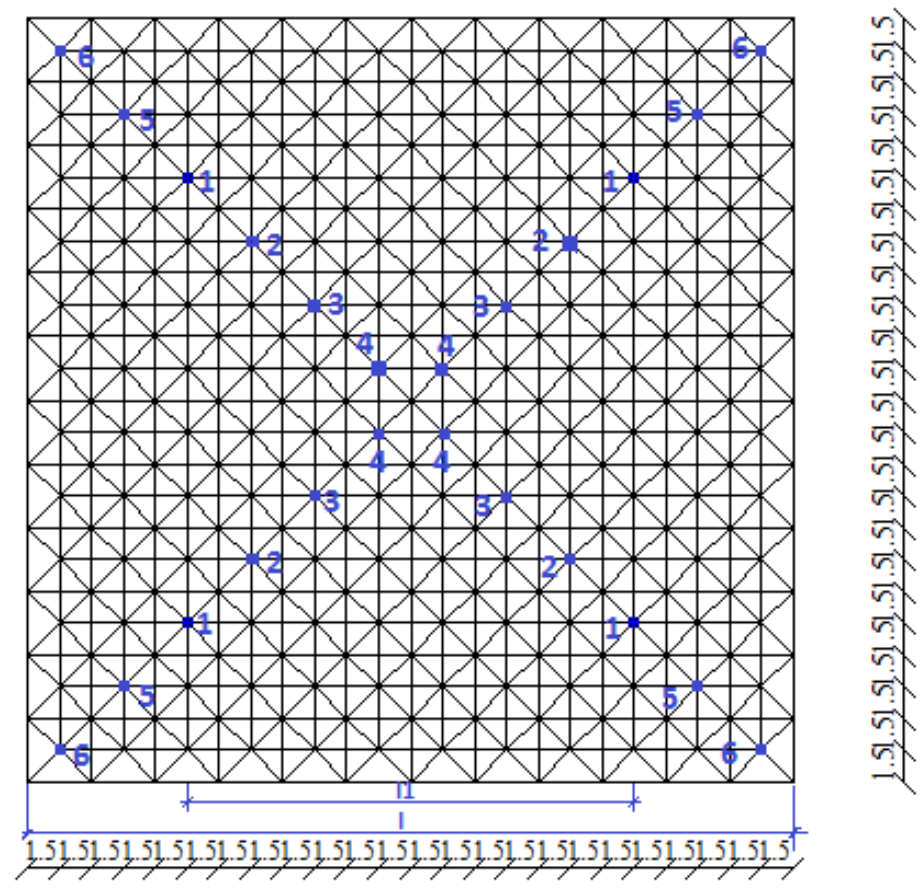

Fig.3. Moving the points support relative to point 1

Table 3.

\begin{tabular}{|c|c|c|c|}
\hline Option number & Type of support & $\begin{array}{c}\text { Weight of structure } \\
\text { without unification, } \mathrm{t}\end{array}$ & Difference, $\%$ \\
\hline 1 & point 1 & 11.433 & $100 \%$ \\
\hline 2 & point 2 & 19.0165 & $166 \%$ \\
\hline 3 & point 3 & 28.1526 & $246 \%$ \\
\hline 4 & point 4 & 34.0889 & $298 \%$ \\
\hline 5 & point 5 & 22.9403 & $201 \%$ \\
\hline 6 & point 6 & 44.4129 & $388 \%$ \\
\hline
\end{tabular}

The calculation results are shown in Table 3, from which it follows that support at point 1 is optimal. All other support conditions are 2-4 times more metal-intensive. As might be expected, greatest structure weight will be at extreme conditions of support - at point 6 at slab corners, which gives the maximum bending moment in the span middle and at point 4 , option with the largest cantilever.

Thus, in absence of technological constraints on supports placement of related to purpose, technology served or architectural requirements, as well as in case of uniform snow load on coating, the best option for placement supports by the metal-intensive criterion is that point 1 with a columns span ratio to span of slab coating ratio $l_{1} / l=21 / 36=0.583$.

A similar calculation was performed for structural slab with dimensions in plan of $24 \times 24$ $\mathrm{m}$, and other parameters did not change. The optimal ratio of spans was obtained at $1_{1} / 1=0.5$. 
And for a slab of $36 \times 24 \mathrm{~m}$, the optimal ratio for aspect calculated slab ratio $1 / 1.5$ is the ratio on abscissa axis $=0.625$, ordinate axis $=0.583$.
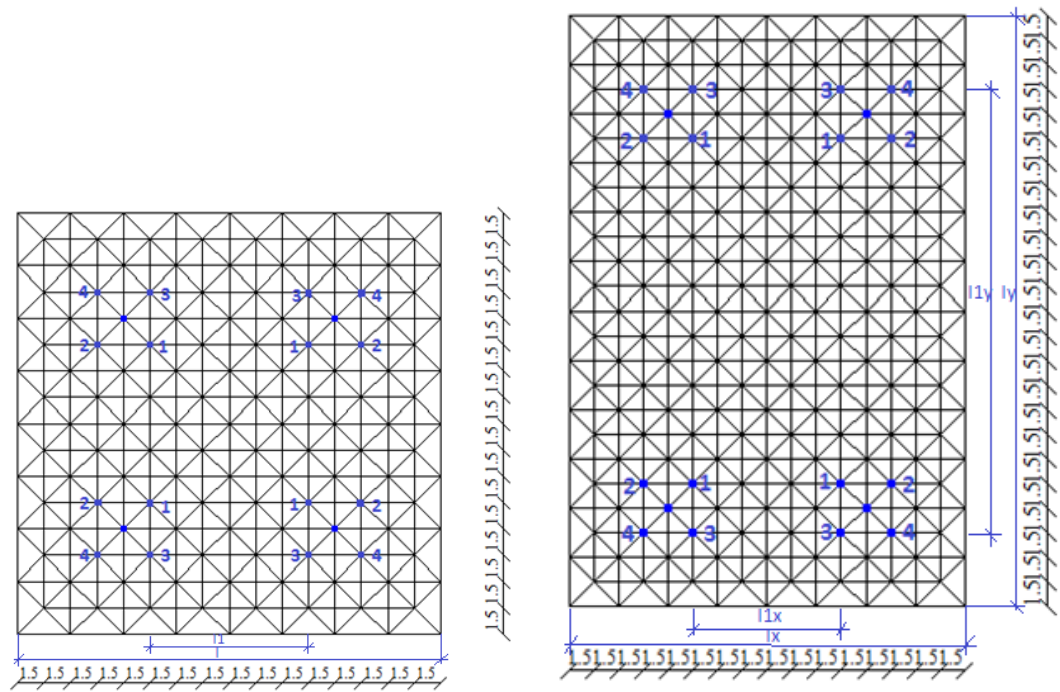

Fig. 4. Construction plan with dimensions of $24 \times 24 \mathrm{~m}$ and $36 \times 24 \mathrm{~m}$

The obtained metal intensity values of structural slab are determined in absence of restrictions on calibers number of structural slab elements. In Russian school of structural steel design, based on taking into account the cost of several factors - material cost, manufacturing cost, delivery and installation, recommendations for calibers number have been developed [12]. Traditionally, it is recommended to use 5-7 caliber sections. This number is accepted on the basis of typification and unification principles, and is widely used in type design. Typical design undoubtedly has a number of advantages, since it applies optimal design schemes, design dimensions, section types, etc. according to complex optimization criteria. Consideration was given to the possibilities of the existing metal structures plants (MSP), the availability of rolling stock, same technology and similarity of equipment, and other such factors, which are now with the market economy is difficult to consider and formalize in general terms, since manufacturing, delivery and installation are determined by competition and depend on market circumstances.

Nevertheless, it seems that designing a structure without limiting the calibers number, or structure dimensions is suboptimal. For example, for the optimal variant of structural slab design under study, 58 calibers are obtained. This is also because it is associated with additional costs to purchase and store such a variety of calibers.

The next stage of study was to calculate the design of structural pavement slab with number limitation of section dimensions.

When limiting the calibers number from 1 to 15 units, the structural roof slab weight increases dramatically. Fig. 5 shows a change graph in structural weight for different numbers of section calibrations. 


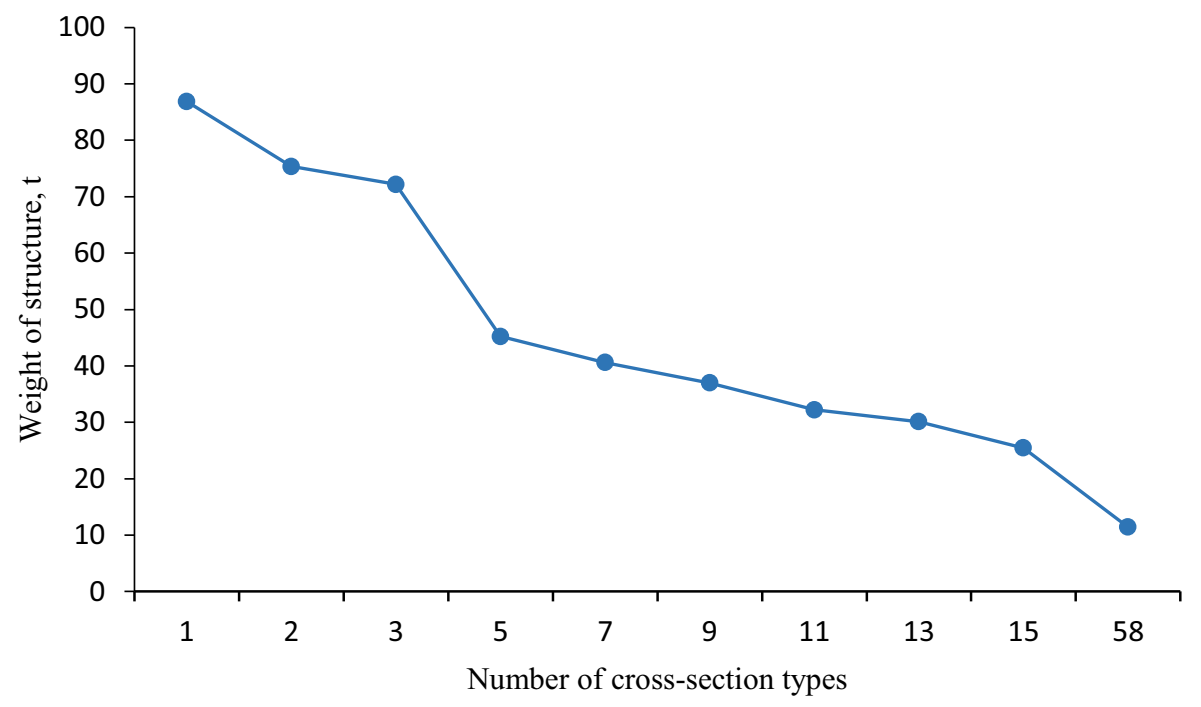

Fig. 5. Dependence diagram of calibers number and structure weight

From the obtained values, it can be seen that when constructing the slab from elements with the same section type, the structure weight increases almost 8 times from 11 to 87 tons. If you take the recommended reference literature recommendation of 5-7 calibers [13], structure weight will increase by almost 4 times. For example, in current prices [14], when the steel cost is from 85 thousand rubles per ton, the difference in consumption cost only for metal of structure main supporting elements will be from 2.8 million rubles.

In next step of study, let's trace how the structure weight changes when the structural slab topology changes. Fig. 6 . presents 6 options of structural slab outline of $36 \times 36 \mathrm{~m}$ pavement with changing the slab height in some areas. The slab is supported at the previously obtained point 1.

\section{Option 1}

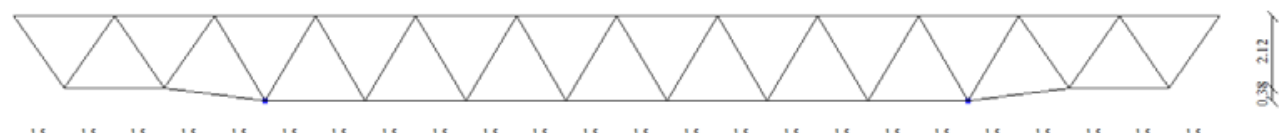

$15,15,15,15,15,15,15,15,15,15,15,15,15,15,15,15,15,15,15,15,15,15,15,15$

Option 2

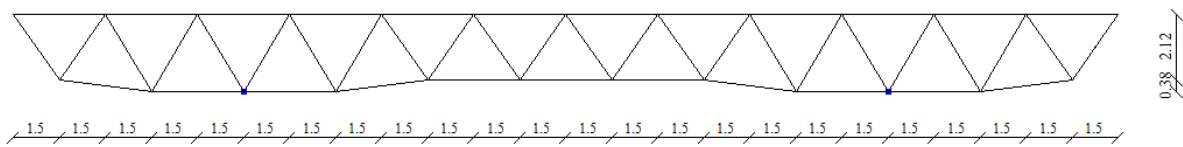


Option 3

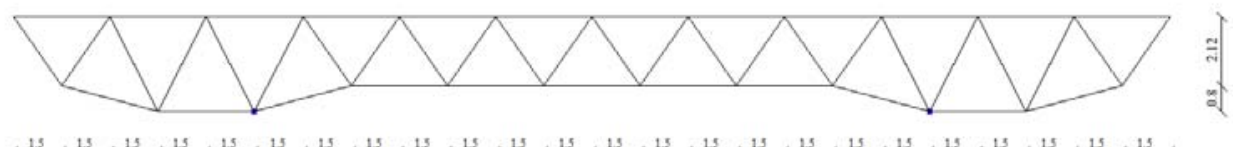

$15,15,15,15,15,15,15,15,15,15,15,15,15,15,15,15,15,15,15,15,13,15,15,15$

Option 4

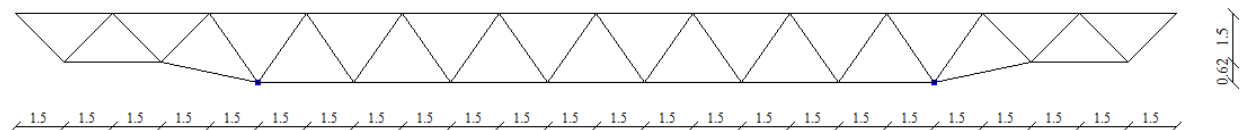

Option 5

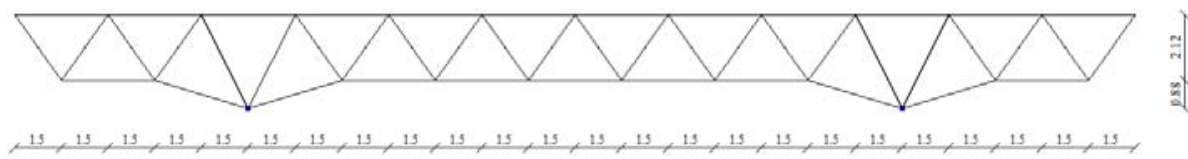

Option 6

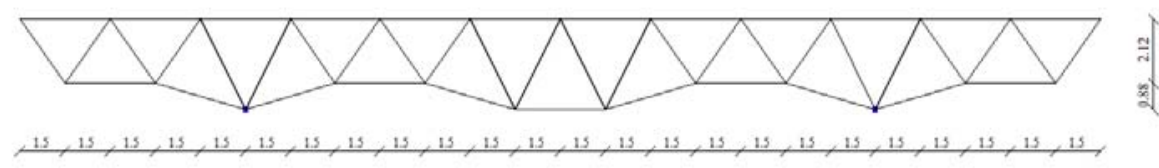

Fig. 6. Changes structural slab outline in height

Table 4 shows the calculations results, which show that a change in structure height, according to option 6 , leads to decrease in structure weight by $8 \%$ relative to original structure at point 1 .

Table 4.

\begin{tabular}{|c|c|c|c|}
\hline \multirow{2}{*}{ Option number } & Height, $\mathrm{m}$ & Weight of structure, $\mathrm{t}$ & Difference, $\%$ \\
\hline Initial data & 2.12 & 11.43 & $108 \%$ \\
\hline 1 & $2.12-2.5$ & 10.87 & $103 \%$ \\
\hline 2 & $2.12-2.5$ & 10.91 & $103 \%$ \\
\hline 3 & $2.1-2,3$ & 10.63 & $101 \%$ \\
\hline 4 & $2.12-1.5$ & 11.86 & $112 \%$ \\
\hline 5 & $2.12-3$ & 10.78 & $102 \%$ \\
\hline 6 & $2.12-3$ & 10.54 & $100 \%$ \\
\hline
\end{tabular}




\section{Conclusions}

We found optimal supports placement for structural roof slab, allowing to obtain a minimum weight structure for slab of $36 \times 36 \mathrm{~m}$ is the columns span ratio to roof slab span $1_{1} / 1=0.583$. For slab with dimensions of $24 \times 24 \mathrm{~m}-1_{1} / 1=0.5$. And for slab $36 \times 24 \mathrm{~m}$, with a side ratio of $1 / 1,5$ - the ratio on abscissa axis $=0.625$, ordinate axis $=0.583$.

Changing the structural slab height in range $0.38-0.88 \mathrm{~m}$ allows you to reduce the structure weight up to $8 \%$.

\section{References}

1. A.A.Zakharenko, T.O. Kotelnikova, S.A. Raschepkina To the design of lightweight metal spatial coatings // The Scientific Heritage. 2020, 43-2 (43), 1-3, (2020)

2. V.S. Agafonkin, M.V. Moiseev, L.A., Isaeva, M.A. Dymolazov, Development and research of structural roof slab of assembly hall training and laboratory building Tupolev KSTU / / / Izvestia of KazGASU. 2010. No. 2, vol. 14, pp. 105-110 (2010)

3. A.V.Nikityuk, A.A. Moskovina Advantages and disadvantages of structural designs // Vestnik (Herald) of PNRPU. Construction and Architecture. 2011. №1. pp.1 (2011)

4. J. Hilton Space grid structures. Oxford: Architectural Press, 19-21 (2000)

5. T. T. Lan, Structural Engineering Handbook ed. C. Wai-Fah, E. M. Lui 2 ed.. New York: CRC Press, 2005. C. 4-5 (2005)

6. A.V. Shilov, V.A.Pogorelov, A.A. Tenyakov, Application of structural coatings in frame type buildings // Engineering journal of Don 2018. №4. - the access Mode: URL: ivdon.ru/ru/magazine/archive/n4y2018/5227 (free access) - Russian language version.

7. A.A. Vasilkin, V.V. Deniakova, Search for optimal design solution of the structural roof slab. in collection of conference Theory of structures: achievements and problems: materials of III All-Russian scientific- practical conference, October 10-12, 2018. Makhachkala / Dagestan State Technical University. - Makhachkala: Publishing house DSTU, 2018. Pp. 26-32 (2018)

8. N.N. Demidov, Features of Structural Structures Supported Calculation by Four Points with Uneven Skew // Industrial and Civil Engineering. 2015. № 1. Pp.50-53 (2015)

9. A.A.Vasilkin, V.V. Deniakova, Regulation of structural roof slab stress-strain state // Engineering journal of Don. 2018. №. 2. - the access Mode: URL: ivdon.ru/ru/magazine/archive/n2y2018/4868 (free access) - Russian language version.

10. D.V. Morozova, E.A. Serova, The problem of feasibility study in design of joints of metal structures // Bulletin of MSCU. 2012. № 12. Pp. 219-223 (2012)

11. I.I. Zueva, S.L. Ivanova, Features of design of "CNIISK" type structural structures // Bulletin of PNIPU. Construction and architecture. 2013. № 1. Pp.91-97 (2013)

12. V.S. Parlashkevich, A.A. Vasilkin, O.E. Bulatov, Design and calculation of metal structures. Training manual. - Moscow: MSCU (2013)

13. Designer's Handbook Metal Structures under the editorship of Academician N.P Melnikov Moscow: Stroyizdat 1980 (1980)

14. Novomoskovsk Metal Structures Plant "Metallist" [Electronic resource]. URL:https://novzmk.ru/ceny-na-izgotovlenie-i-montazh-metallokonstrukcij.html (date of the reference 24.01.2021) 